\title{
Effects of active carbon pore size distributions on adsorption of toxic organic compounds
}

\author{
Peter Branton • Robert H. Bradley
}

Received: 25 November 2009 / Accepted: 18 October 2010 / Published online: 6 November 2010

(C) The Author(s) 2010. This article is published with open access at Springerlink.com

\begin{abstract}
The use of active carbons for the removal of toxic organic compounds, for example from air or smoke, is of significant interest. In this paper, the equilibrium and dynamic adsorption characteristics of two active carbons are explored; one microporous coconut based and the other micro-mesoporous derived from a synthetic resin. Benzene, acetaldehyde and acrylonitrile were chosen as the probe toxicant vapours and adsorption was measured at a temperature of $298 \mathrm{~K}$. The nitrogen equilibrium data (at $77 \mathrm{~K}$ ), analysed using the BET, Dubinin-Radushkevich equations and DFT models, showed a higher overall adsorption capacity, more supermicroporosity and a higher proportion of pores wider than $2 \mathrm{~nm}$ for the synthetic resin based material. A micropore distribution biased toward the ultramicropore widthrange was observed for the nutshell material. As a consequence, the characteristic adsorption energies in micropores are higher for the nutshell material than the resin based carbon. The effect of these different pore size characteristics on the adsorption kinetics, obtained by fitting the data to the linear driving force (LDF) model, is that the resulting adsorption rate constants are higher across much of the relative pressure range $\left(p / p^{s}\right)$ studied for the resin based carbon compared to the nutshell material. Significantly, the wider pores of the resin-based carbon result in higher rates of adsorption in the micropore filling domain. When evaluated
\end{abstract}

P. Branton ( $\varangle)$

Group Research and Development, British American Tobacco, Regents Park Road, Millbrook, Southampton SO15 8TL, UK e-mail: peter_branton@bat.com

\section{R.H. Bradley}

Carbon Technology, MatSIRC Ltd., Penrith, Cumbria

CA10 1NW, UK

e-mail: matsirc@btinternet.com under dynamic conditions in cigarette smoke, improved toxicant removal was observed using the resin based carbon.

Keywords Active carbon · Adsorption · Pore size distribution $\cdot$ Smoke $\cdot$ Toxic organic compounds

\section{Introduction}

Active carbons are very effective adsorbents for a wide range of toxic organic vapour phase species encountered in domestic and industrial situations (Bansal and Goyal 2005). They are used in a wide range of separation and recovery processes. For example, they are the main adsorbent used in military and many industrial respiratory protection systems. Their incorporation into the filters of cigarettes can also be used for the adsorption of selected toxicants found in cigarette smoke. The major factors governing the selection of active carbons for this use are the pore characteristics, i.e. the pore size distribution and volume. Notionally, the ideal carbons should have sufficient microporosity to allow adsorption of the volume of volatiles produced during smoking, plus a level of wider $(>2 \mathrm{~nm})$ transport pores to allow dynamic adsorption at rates which give effective toxicant removal at the attendant flow rates; these characteristics are difficult to find in one single carbon. A carbon screening method has previously been described (Mola et al. 2008; Branton et al. 2009) but as yet there are no models to predict carbon activity under the conditions encountered during the smoking process. This paper reports the results from a preliminary study, the objectives of which were to quantify the adsorption volume and kinetic properties of different carbons for evaluation in a cigarette filter and to establish protocols for comparing different carbon/vapour systems. 
The equilibrium and dynamic adsorption characteristics of two active carbons (one coconut shell based and one based on a synthetic resin, both with very different pore size distributions) have been studied using nitrogen adsorption at $77 \mathrm{~K}$ and a small range of organic vapours (benzene, acetaldehyde and acrylonitrile) at $298 \mathrm{~K}$. Pore structure has been studied using the Dubinin approach (Dubinin 1989; Dubinin and Radushkevich 1947) and its more recent modifications by Stoeckli (Stoeckli 2001; Stoeckli et al. 2002) to derive micropore volume data, to derive a quantitative measure of the micropore size distributions for each carbon and to assess the energies of adsorption within micropores of differing sizes. For completeness, the classical BET method has also been applied to the data. The DFT method has been used to extract additional pore size distributions from the nitrogen data. Kinetic profiles have been analysed using the Linear Driving Force method (Reid and Thomas 2001; Fletcher et al. 2007; Rutherford and Coons 2004) where adsorption by an active carbon follows a pseudo first-order mass transfer process from the free adsorptive phase to the carbon surface/porosity. This allows the determination of an adsorption rate constant, $k$, which allows comparisons of adsorption kinetics for different adsorbate/carbon systems which can then be correlated with pore characteristics. The effects of these fundamental carbon parameters on smoke toxicant removal, specifically the three vapours mentioned above, has then been studied using a standard smoking test to assay these toxicant reductions by incorporating each carbon into the cigarette filter system.

\section{Theory}

The Dubinin-Radushkevich (DR) equation (Dubinin and Radushkevich 1947; Dubinin 1989), and its extensions (Stoeckli 2001; Stoeckli et al. 2002), has been used to derive micropore volume $\left(W_{0} / \mathrm{cm}^{3} \mathrm{~g}^{-1}\right)$ and pore size distribution information from static equilibrium isotherm data. In its most general form, it is written

$W=W_{0} \exp \left[-\left(A / \beta E_{0}\right)^{2}\right]$

where $W_{0}$ is the micropore volume of the carbon, $W$ is the equilibrium adsorption volume at adsorption potential $A=R T \ln p^{s} / p\left(\mathrm{~kJ} \mathrm{~mol}^{-1}\right), p$ and $p^{s}$ are respectively the equilibrium and the saturated vapour pressures of the adsorptive, $R$ is the gas constant and $T$ the absolute temperature of adsorption; $\beta$ describes the adsorptivity of the vapour compared to a suitable reference (traditionally $\beta \mathrm{C}_{6} \mathrm{H}_{6}=1$ ) and $E_{0}\left(\mathrm{~kJ} \mathrm{~mol}^{-1}\right)$ is the characteristic adsorption energy within micropores. The adsorption potential $(-A)$ is assumed to be equal to the molar free energy of adsorption and therefore sufficient to remove one mole of free vapour adsorptive to the liquid phase. With the opposite sign, it is equal to the molar work of adsorption. In practical terms it is found that, from (1), plotting the Type I isotherm for a microporous carbon in the form $\log W\left(\mathrm{~cm}^{3} \mathrm{~g}^{-1}\right)$ versus $\left[\ln p^{s} / p\right]^{2}$ leads to a linear plot from which $W_{0}\left(\mathrm{~cm}^{3}\right.$ liquid) and $E_{0}$ can be obtained. Frequently, and for various reasons, deviations from linearity are observed in such plots; these have been discussed in detail elsewhere (Marsh and Rand 1970) but usually the main linear region, which encompasses most of the micropore filling region of the adsorption isotherm, is sufficient to allow a confident extrapolation to the y-axis to obtain $W_{0}$; this method gives a straightforward and sound basis for comparing the micropore capacities of different carbons. Replacing the square term in (1) with an exponential $(n)$ which describes the micropore size distribution leads to the more general Dubinin-Astakhov equation (Dubinin and Astakhov 1971). The difference between $W_{0}$ from (1) and the total adsorbed volume $\left(V_{T}\right)$ at $p / p^{s}$ near to saturation (0.95-0.98 in practical terms) allows a first-order approximation of the wider $(>2 \mathrm{~nm})$ pores.

In the development of Dubinin's theory, early experiments using different sized molecular probes suggested that the structural constant $(B)$ of the original DR equation, effectively $E_{0}$ of (1), was related to the size of the micropores. Subsequent studies using small angle x-ray scattering showed $E_{0}$, to be an inverse function of the gyration radius of the micropores (Dubinin et al. 1964) and various subsequent studies, for example (Stoecki 1997) have shown an empirical correlation between the micropore width $(L / \mathrm{nm})$ and $E_{0}$ to be given by:

$L / \mathrm{nm}=10.8 /\left(E_{0}-11.4\right)$

which is now accepted to apply for equilibrium adsorption within the average micropore width range $(0.4<L<2 \mathrm{~nm})$.

In practice, adsorption is significantly influenced by a second factor-the rate of adsorption under the operating flow conditions. Dynamic adsorption models essentially reflect the mechanisms of diffusion in porous carbons. It was concluded (Rao et al. 1985) that two major barriers to diffusion existed: (i) pore entry and (ii) diffusion along the pore. The rate limiting step in highly microporous carbons is pore entry. A number of dynamic models based on Fickian, barrier resistance/Fickian and linear driving force (LDF) model (Reid and Thomas 2001; Fletcher et al. 2007; Rutherford and Coons 2004) have been used to describe adsorption by granular active carbons. For microporous carbons, where pore entry is rate determining, the kinetics follow the LDF model which takes the following form:

$M_{t} / M_{e}=1-\exp (-k t)$

where $M_{t}$ is the mass uptake of adsorbate in the pores at time $t, M_{e}$ is the mass uptake at equilibrium and $k$ is the 
Table 1 Adsorbate

characteristics at $T_{\text {ads }}$

\begin{tabular}{lrllll}
\hline & $\begin{array}{l}P^{s} \\
\mathrm{mbar}\end{array}$ & $\begin{array}{l}V_{m} \\
\mathrm{~cm}^{3} \mathrm{~mol}^{-1}\end{array}$ & $\begin{array}{l}\text { Molecular area } \\
\left(\times 10^{-20} \mathrm{~m}^{2}\right)\end{array}$ & $\begin{array}{l}\text { Liquid density } \\
\left(\mathrm{g} \mathrm{cm}^{-3}\right)\end{array}$ & $\beta$ \\
\hline $\mathrm{N}_{2} / 77 \mathrm{~K}$ & 989.4 & 17.3 & 16.2 & 0.808 & 0.39 \\
Acetaldehyde & 1198.0 & 55.9 & 22.42 & 0.785 & 0.63 \\
Acrylonitrile & 144.7 & 65.5 & 24.94 & 0.806 & 0.74 \\
Benzene & 126.6 & 88.9 & 30.52 & 0.874 & 1.00 \\
\hline
\end{tabular}

kinetic rate constant. Using this approach, plots of $M_{t} / M_{e}$ versus $t$ allow comparison of the relative rates of uptake of various adsorptives on a given carbon whereas plots of $\ln \left(1-M_{t} / M_{e}\right)$ against $t$ are linear if LDF mass transfer kinetics are operating. The rate constant $(k)$ can be derived from the gradient of the plot, or, as here, by direct numerical means, and is generally found to increase with pressure and to also be temperature sensitive and specifically sensitive to the precise characteristics of the adsorptive such as molecular size and shape. Nitrogen and oxygen have been observed to follow the LDF model on molecular sieve type carbons with values of $k$ varying by a factor of 25. Carbon dioxide, by contrast, exhibits a change in diffusion mechanism from pore entry limited to in-pore diffusion as the pressure increases and consequently a change in the bestfit model from LDF through barrier resistance/diffusion to Fickian diffusion is observed.

\section{Experimental}

Microporous coconut based activated carbon (Ecosorb CX, Jacobi Carbon) was prepared via steam activation of coconut char. Micro-mesoporous resin based activated carbon was prepared via a proprietary process. Granular carbon with particle size of the order of $0.3-0.6 \mu \mathrm{m}$ was evaluated throughout.

Data for the adsorption of nitrogen at $77 \mathrm{~K}$ and the smoke constituent organic vapours: acetaldehyde, acrylonitrile and benzene at $298 \mathrm{~K}$ by two active carbons, one nutshell based and the other resin-based, have been measured gravimetrically using a Hiden Intelligent Gravimetric Analyser.

Approximately $100 \mathrm{mg}$ of carbon was loaded into a small cylindrical micromesh stainless steel sample container and a quartz wool plug used to prevent loss during pumping/experimentation. The sample was suspended within the adsorption hang-down tube within a furnace, to outgas, or within a thermostatic bath for adsorption measurements. Outgassing was carried out using a pump rate of $200 \mathrm{mbar} / \mathrm{min}$ to a base pressure $<3 \times 10^{-7} \mathrm{mbar}$ for a minimum period of 15 hours at approximately $100^{\circ} \mathrm{C}$.
Loaded (as stored) carbon weight, weight loss on drying values and base pressure were monitored and isotherms expressed as weight or liquid volume uptakes per gram of outgassed carbon. A rate of $120 \mathrm{mbar} / \mathrm{min}$ was used to introduce adsorptive vapours and real-time analysis was used to determine the equilibrium uptake and to change the data collection time for each isotherm point with a target that the weight is $99 \%$ relaxed (quoted as equilibrium $\pm 1 \%$ uptake).

Adsorptives were introduced as pure vapour from Analar grade liquids (nominal $99.99 \%$ purity) under high vacuum which was achieved using a 60 1/s turbo-molecular drag and dry membrane backing pump to minimise sample/adorptive contamination. Adsorbate physical data at the measurement temperature $\left(T_{\text {ads }}\right)$ are shown in Table 1.

From the resulting equilibrium adsorption isotherm data, specific surface area values have been derived using the BET equation (Brunauer et al. 1938). Total pore volumes $\left(V_{t}\right)$ are given at relative pressures of 0.95 (nominal). Micropore $\left(W_{0}\right)$ volumes and size distributions have been obtained using the Dubinin approach. Micropore size distributions have been characterised using the Dubinin method applied to the nitrogen data and compared with DFT analysis using more recent methods (Jagiello et al. 2007). The latter also identifies adsorption occurring in meso and macropores and these have therefore been compared to $V_{t}-W_{0}$ volumes derived using more traditional methods. The relative rates of adsorption of the various vapours have been derived by fitting time resolved adsorption uptake data to a first order rate expression using numerical methods.

For smoking tests, $60 \mathrm{mg}$ of each granular carbon was weighed into the cavity of a cigarette filter. As a control, cigarettes were also prepared with an empty filter cavity. Cigarettes were conditioned at $22^{\circ} \mathrm{C}$ and $60 \%$ Relative $\mathrm{Hu}$ midity for 3 weeks prior to smoking.

Smoke toxicant yields were measured using a standard ISO smoking regime whereby cigarettes were smoked using a puff volume of $35 \mathrm{~cm}^{3}$, puff duration of $2 \mathrm{~s}$ and puff interval of one minute (Thomsen 1992). The smoke volatile species were collected and analysed using GCMS (http://www.bat-science.com). The mean values of three replicates of 5 cigarettes were used. Percentage removals were calculated relative to the cigarette containing no carbon in the filter. 


\section{Results and discussion}

Nitrogen isotherms at $77 \mathrm{~K}$ and acetaldehyde, acrylonitrile and benzene isotherms at $298 \mathrm{~K}$ are shown in Figs. 1a-1d for both carbons. Characteristic parameters from the equilibrium isotherms are summarised in Table 2. The isotherms recorded for all of the vapours on the nutshell carbon are classical Type I with a relatively sharp knee (the exact radius depending on the specific probe vapour) at $p / p^{0}<0.1$, followed by a plateau indicating that little significant adsorption occurs after micropore filling has ceased and that the Pore Size Distributions (PSDs) are effectively monomodal and $<2 \mathrm{~nm}$ average width. Qualitatively, the knee for the benzene isotherm appears tightest, suggesting that the strongest interaction with the carbon's microporosity occurs for this vapour.

For the resin based carbon, significantly different isotherms are observed for all vapours; that is to say, their first parts i.e. at $p / p^{s}<0.2$, which contain the micropore filling region, are Type I in character. However, the knees are, in all cases, more rounded than those in the plots from the nutshell carbon indicating a broader distribution of micropores. Unlike the curves for the nutshell carbon, the isotherms then show positive curvature (rather than a plateau) which is indicative of monolayer-multilayer adsorption and capillary condensation in wider pores. This second part of the curve is therefore of Type IV character and small hysteresis loops are observed for benzene and acrylonitrile. Overall, this behaviour is characteristic of a distribution of pores part of which is in the meso-macro size range ( $>2 \mathrm{~nm}$ ).

Comparison of the micropore volumes and size distributions of the two carbons by application of the Dubinin method to the nitrogen data, reveals both the overall higher volume of the resin carbon and also that the distribution for the nutshell carbon is relatively narrow and mostly in the 0.5-1.0 $\mathrm{nm}$ size range compared to the resin-based carbon where a significantly higher proportion of supermicropores (1-2 nm) are present (Fig. 2).

DFT analysis of these data (Fig. 3) confirms the higher proportion of supermicropores in the resin based carbon and appears to indicate a bi-modal micropore distribution. This latter point requires more investigation; the DFT method is well known but requires a wider validation. The DFT approach is not limited to the micropore size range and may be used for pore analysis up to slit-widths of around $300 \AA$. Here it also highlights the relatively high volume of wider pores, centred at an $80 \AA$ slit-width, for the resin carbon which may contribute to its transport properties and hence the higher rates of adsorption reported below. Table 2 shows that the values of $V_{t}-W_{0}$ values for this material lie in the range 0.21 to $0.55 \mathrm{~cm}^{3} \mathrm{~g}^{-1}$. These wider pores are not evident for the nutshell material and the corresponding $V_{t}-W_{0}$ values are all around $0.01-0.02 \mathrm{~cm}^{3} \mathrm{~g}^{-1}$.
From the nitrogen data, the BET equation gives specific surface areas of $980 \mathrm{~m}^{2} \mathrm{~g}^{-1}\left( \pm 40 \mathrm{~m}^{2} \mathrm{~g}^{-1}\right)$ for the nutshell carbon and $1660 \mathrm{~m}^{2} \mathrm{~g}^{-1}\left( \pm 40 \mathrm{~m}^{2} \mathrm{~g}^{-1}\right)$ for the resinbased carbon (see Table 1 ). These values are calculated using a geometric mean area of $16.2 \times 10^{-20} \mathrm{~m}^{2}$ for the adsorbed $\mathrm{N}_{2}$ molecules as is usual for this method. Specific surface areas derived from the other vapours, using molecular areas from standard sources (Gregg and Sing 1982; Adamson 1990), are also given. Benzene is frequently used in adsorption studies of active carbons and is traditionally used as a reference to calculate the affinity coefficient $(\beta)$ in the Dubinin method (Dubinin and Timofeyev 1946; Sugden 1924). Its adsorption behaviour on carbons is therefore well understood. There have, however, been few, if any, previous detailed studies of the adsorption of acetaldehyde and acrylonitrile on carbon surfaces and, hence a degree of caution is needed since the precise characteristics of the molecules when adsorbed on carbon-planes or confined within a porous network are not fully understood.

For the nutshell carbon, the organics give area values which are lower than those from the nitrogen even though their adsorption temperature is relatively high and activated diffusion, which might well occur within the micropore structure for nitrogen adsorbed at $77 \mathrm{~K}$, might be expected to be absent, or at least reduced, for the organic vapours. It is highly likely that there is some molecular size selectivity occurring within the micropore filling region. Since the molecular shapes and orientations of the adsorbed organics are unknown, no further corrections of geometric area have been attempted. For the resin based carbon, the areas from the organic vapours are all around 1100 to 1300 , which is a little low compared to the nitrogen value $\left(1660 \mathrm{~m}^{2} \mathrm{~g}^{-1}\right)$ and any molecular size ordering is less well defined.

Analysis of the data using the Dubinin-Radushkevich models gives micropore $(<2 \mathrm{~nm})$ volumes $\left(W_{0}\right)$ of 0.38 to $0.43 \mathrm{~cm}^{3} \mathrm{~g}^{-1}$ for the nutshell carbon and significantly higher values, 0.57 to $0.75 \mathrm{~cm}^{3} \mathrm{~g}^{-1}$, for the resin based material. The values of $V_{t}$ for the nutshell material are very similar to its $W_{0}$ figures ( 0.40 to $0.45 \mathrm{~cm}^{3} \mathrm{~g}^{-1}$ ) whilst those from the resin carbon are significantly higher than the corresponding $W_{0}$ values, i.e. in the range 0.9 to $1.30 \mathrm{~cm}^{3} \mathrm{~g}^{-1}$. Hence the $V_{t}-W_{0}$ for the respective carbons confirm the near monomodal Pore Size Distribution (PSD) for the nutshell material, with very little adsorption in wider pores, and the bimodal PSD of the resin carbon which are qualitatively evident from the isotherm comparisons described above. The levels of meso/macro porosity present in the resin carbon are adsorbate-specific and vary from $23 \%$ to $58 \%$ of $V_{t}$.

A more detailed analysis and comparison of the data sets plotted in the form of (1) reveals a number of interesting features. Plots for the resin based carbon are linear in the very low pressure region (high $\left(\log p^{s} / p\right)^{2}$ range), whereas the plots for the nutshell carbon show a negative deviation from 
Fig. 1 Equilibrium isotherms for nitrogen at $77 \mathrm{~K}$ and acetaldehyde, acrylonitrile and benzene at $298 \mathrm{~K}$ on nutshell and resin based carbon. Different symbols denote different runs, open symbols denote adsorption, closed symbols denote desorption (a) Nitrogen at $77 \mathrm{~K}$

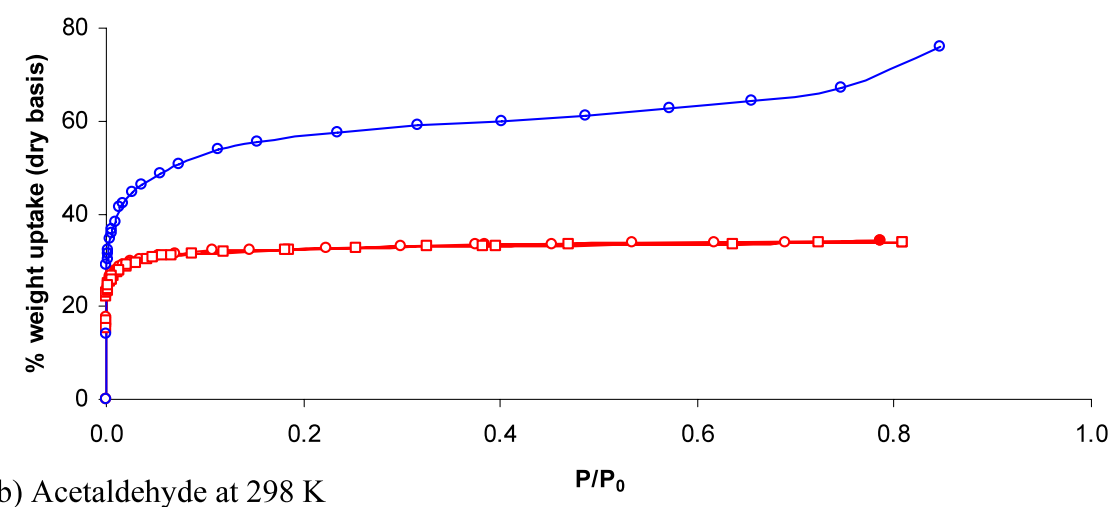

(b) Acetaldehyde at $298 \mathrm{~K}$

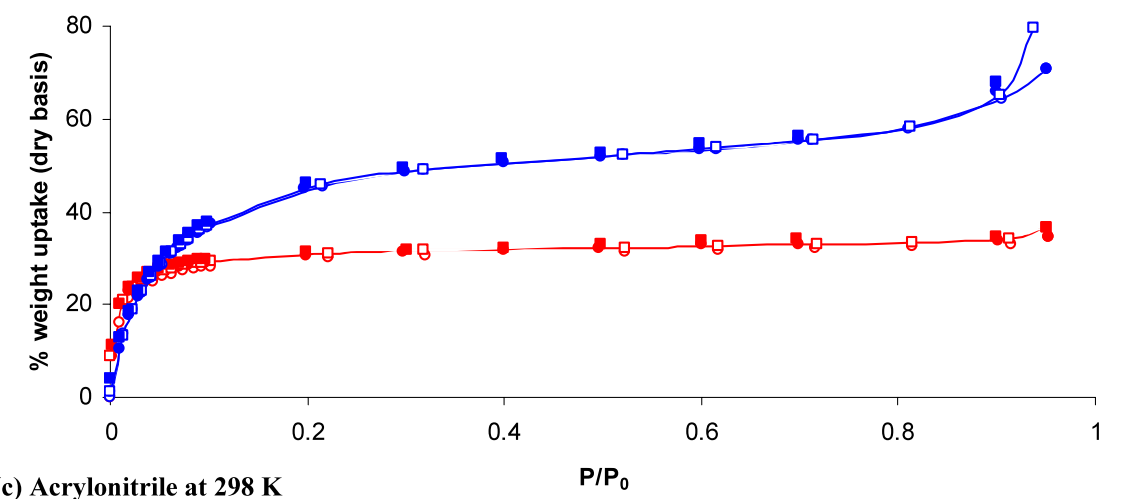

(c) Acrylonitrile at $298 \mathrm{~K}$

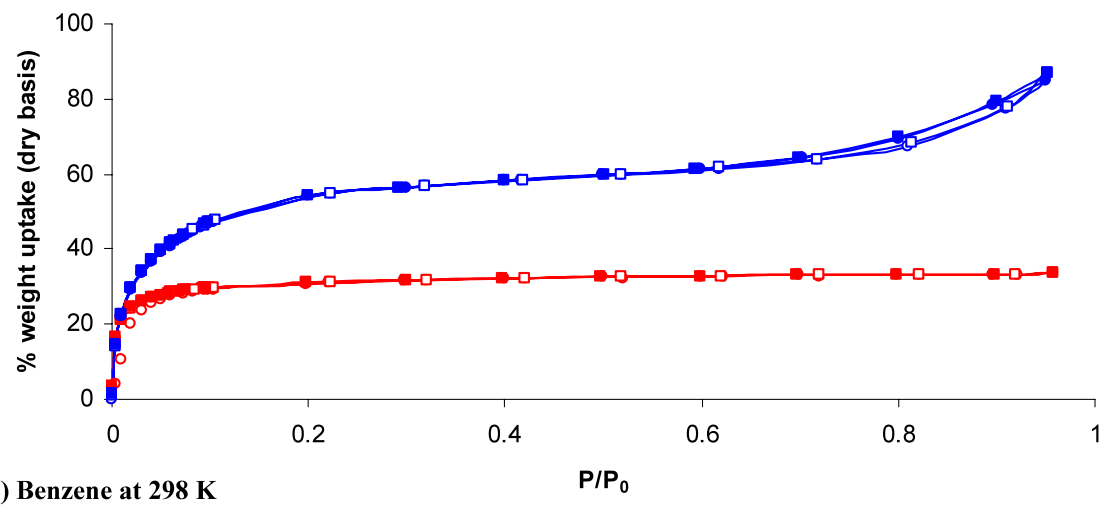

(d) Benzene at $298 \mathrm{~K}$

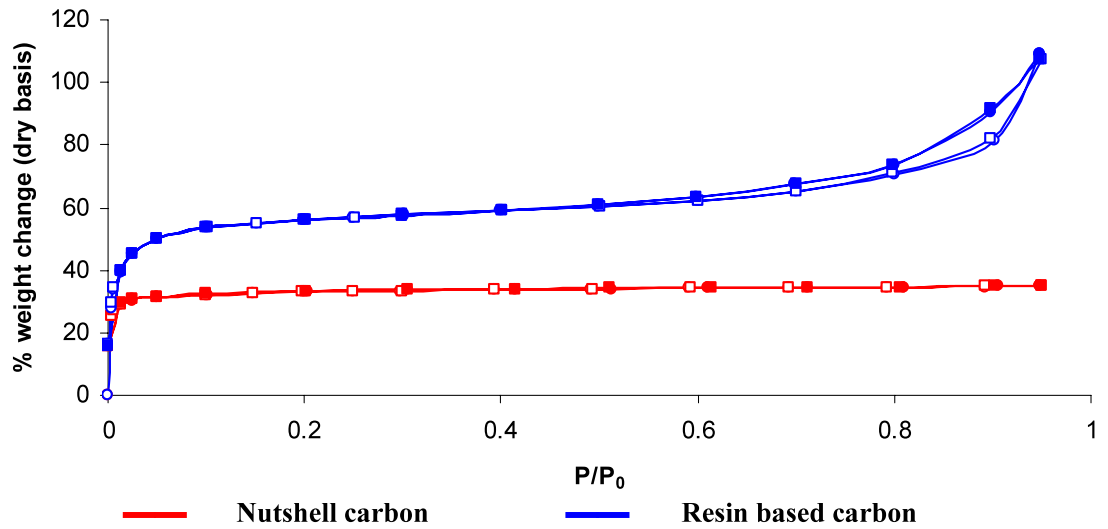


Table 2 Carbon characteristic data determined from isotherm measurements

\begin{tabular}{lllllll}
\hline Adsorbate & $\begin{array}{l}\text { BET Area } \\
\mathrm{m}^{2} \mathrm{~g}^{-1}\end{array}$ & $\begin{array}{l}W_{0} \\
\mathrm{~cm}^{3} \mathrm{~g}^{-1}\end{array}$ & $\begin{array}{l}V_{t} \\
\mathrm{~cm}^{3} \mathrm{~g}^{-1}\end{array}$ & $\begin{array}{l}V_{t}-W_{0} \\
\mathrm{~cm}^{3} \mathrm{~g}^{-1}\end{array}$ & $\begin{array}{c}E_{0} \\
\mathrm{~kJ} \mathrm{~mol}^{-1}\end{array}$ & $\begin{array}{l}L \\
\mathrm{~nm}\end{array}$ \\
\hline $\begin{array}{l}\text { Nutshell carbon } \\
\text { Acetaldehyde }\end{array}$ & & & & & & \\
Acrylonitrile & 780 & 0.43 & 0.44 & 0.01 & 31.03 & 0.55 \\
Benzene & 850 & 0.41 & 0.42 & 0.01 & 28.10 & 0.64 \\
Nitrogen (at 77 K) & 980 & 0.38 & 0.40 & 0.02 & 31.76 & 0.53 \\
Resin based carbon & & 0.40 & 0.42 & 0.02 & 24.70 & 0.81 \\
Acetaldehyde & 1270 & 0.69 & 0.90 & 0.21 & & 19.49 \\
Acrylonitrile & 1310 & 0.75 & 1.05 & 0.30 & 16.59 & 2.10 \\
Benzene & 1150 & 0.70 & 1.25 & 0.55 & 20.08 & 1.24 \\
Nitrogen (at 77 K) & 1660 & 0.57 & 0.94 & 0.37 & 16.29 & 2.20 \\
\hline
\end{tabular}

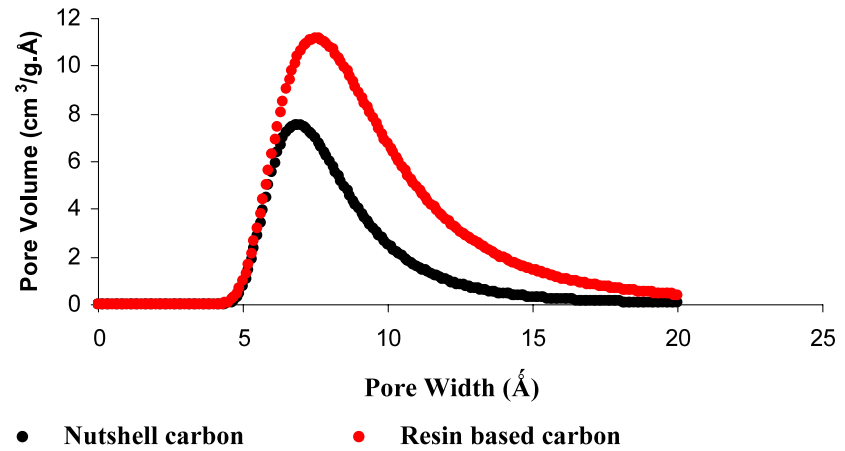

Fig. 2 Dubinin-Astakhov (D-A) PSD data using nitrogen adsorption at $77 \mathrm{~K}$

linearity in the very low pressure region, i.e. where the narrowest pores of the distribution are filling. This is illustrated in Fig. 4 for acrylonitrile which typifies this behaviour. Similar plots are also observed for acetaldehyde and benzene. This type of low pressure negative deviation, termed Type A (Marsh and Rand 1970), is most frequently attributed to activated diffusion in ultra-microporosity; this occurs when the low kinetic energy of the adsorbate molecules retard the adsorption rate which, over the normal timescale of adsorption experiments, effectively leads to a pseudo, or apparent, adsorption equilibrium. The recorded uptake is low compared to the true value which would be achieved if the system was given an extended equilibration time (variously, days, weeks and months have been reported to result in linear plots, for example, Toda et al. 1970). This effectively is absent, or far less prominent, in the plots for the resin based carbon data which is consistent with the supermicroporosity detected for this material and also with the suggestion that the wider pores, indicated by the high values of $V_{t}-W_{0}$, lead to superior adsorption kinetics for this material. The last data point in the plot given in Fig. 4 by the resin carbon actually shows a very slight positive deviation from linearity but this is close to error and makes further analysis unjustified. DR plots with true curvature, convex toward the pressure axis, Type B in the Marsh \& Rand classification have been mainly reported for carbon dioxide.

The values for the characteristic adsorption energy $\left(E_{0} / \mathrm{kJ} \mathrm{mol}^{-1}\right)$ from (1) for each system are given in Table 2 which also gives the average micropore width $(L / \mathrm{nm})$ obtained from (2). Where negative deviations in the plots occur, the values shown are calculated from the second linear regions of the plots, which describe the main, equilibrium, adsorption in micropores. The energy values for the nutshell carbon are higher than those from the resin materials with the resulting values of $L$ all being $<1 \mathrm{~nm}$ which is characteristic of ultramicoporosity. The $L$ values for the resin based carbon are all $>1 \mathrm{~nm}$ and characteristic of supermicropores. Where negative deviations are observed, i.e. where the first data points give a linear region of higher slope than the second, main micropore-filling region of the plot, then a false, lower, energy results to that expected for ultramicroporefilling as discussed previously (Bradley 1991).

The effects of the two different PSDs on the relative adsorption kinetics for the two carbons and for the suite of smoke constituents are apparent in the rate constants $\left(\mathrm{K} \mathrm{s}^{-1}\right)$ derived using (3) as shown in Table 3. Representative rates are shown for the micropore-filling region and are compared in terms of similar ranges of adsorption potential $\left(A=R T \ln p^{s} / p\left(\mathrm{~kJ} \mathrm{~mol}^{-1}\right)\right)$ for each adsorptive which removes the physical variables $p$ and $p^{s}$ and the experimental variable $T$.

Comparison of the rate constants for the organic vapours for the micropore-filling regions of the two carbons shows the effect of the large proportion of meso and macro pores present in the resin based material is apparent as higher rate constants observed for acetaldehyde, and benzene compared to those from the nutshell carbon where diffusion is presumably limited by pore-entry (the so called 'barrier resistance 
Fig. 3 DFT analysis using nitrogen adsorption at $77 \mathrm{~K}$
Fig. 4 Comparison of typical Dubinin-Radushkevich plots for acrylonitrile at $298 \mathrm{~K}$ on nutshell and resin based carbons showing the negative (Type A) deviations for the nutshell material and near-linearity across the micropore-filling range of data for adsorption by the resin based carbon

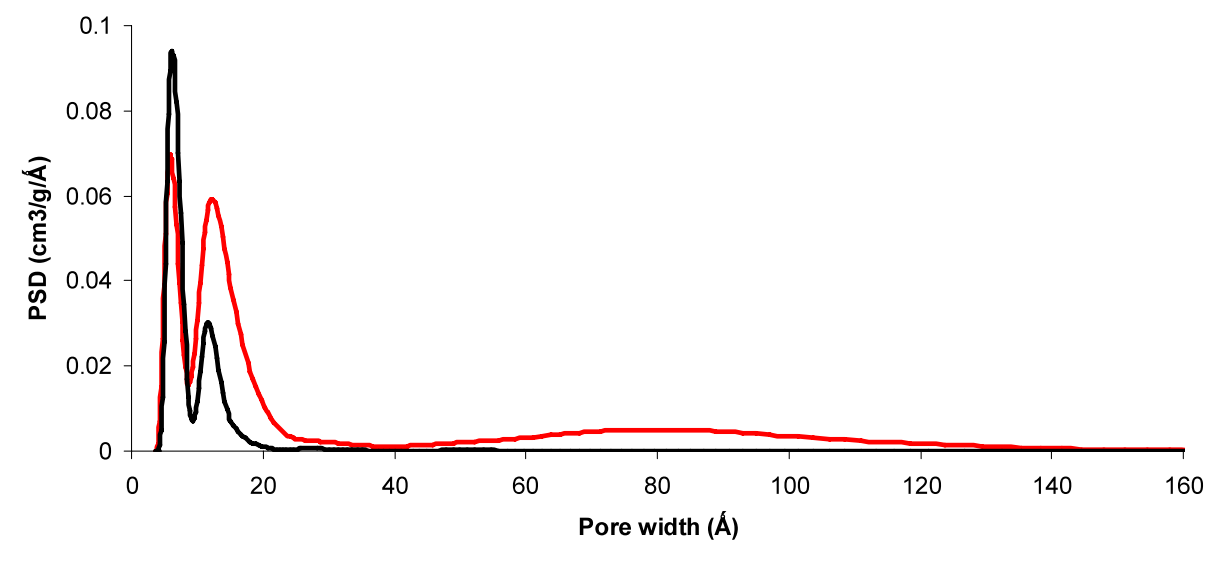

- Nutshell carbon $\quad$ Resin based carbon

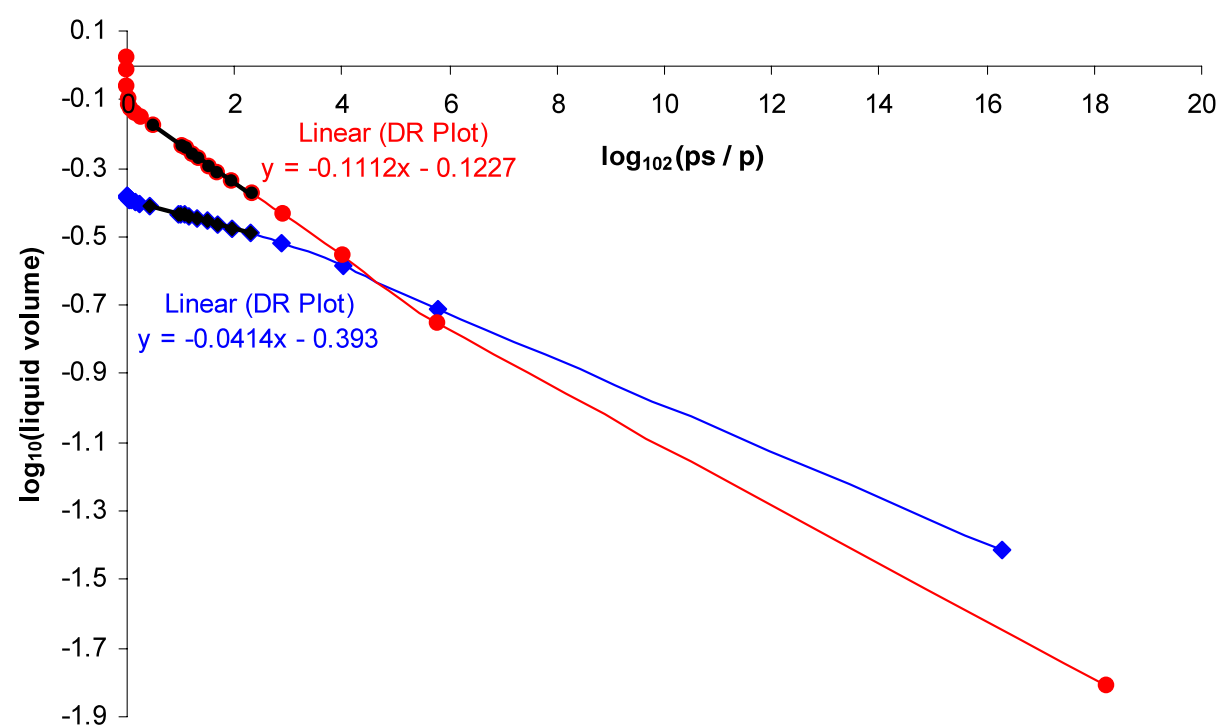

Resin based carbon
Table 3 Rate Constants $K$ $\left(\times 10^{-2}\right) \mathrm{s}^{-1}$ and corresponding Polanyi adsorption potentials $\left(A=R T \ln p^{s} / p\right)$ for micropore-filling

\begin{tabular}{|c|c|c|c|c|c|c|}
\hline \multirow{2}{*}{$\begin{array}{l}\text { Carbon } \\
\text { Adsorbate }\end{array}$} & \multicolumn{3}{|l|}{ Nutshell } & \multicolumn{3}{|l|}{ Resin based } \\
\hline & $p / p^{s}$ range & $\begin{array}{l}K \\
\times 10^{-2} \mathrm{~s}^{-1}\end{array}$ & $\begin{array}{l}A \\
\mathrm{~kJ} \mathrm{~mol}^{-1}\end{array}$ & $p / p^{0}$ range & $\begin{array}{l}K \\
\times 10^{-2} \mathrm{~s}^{-1}\end{array}$ & $\begin{array}{l}A \\
\mathrm{~kJ} \mathrm{~mol}^{-1}\end{array}$ \\
\hline Acetaldehyde & $0.019-0.033$ & 1.29 & 10.97 & $0.014-0.023$ & 1.74 & 11.24 \\
\hline \multirow[t]{2}{*}{$289 \mathrm{~K}$} & $0.033-0.043$ & 1.01 & 10.70 & $0.032-0.042$ & 1.57 & 10.75 \\
\hline & $0.043-0.053$ & 1.02 & 10.57 & $0.042-0.053$ & 2.09 & 10.59 \\
\hline Acrylonitrile & $0.010-0.020$ & 3.78 & 11.82 & $0.010-0.020$ & 2.04 & 11.72 \\
\hline \multirow[t]{2}{*}{$298 \mathrm{~K}$} & $0.020-0.030$ & 2.43 & 11.31 & $0.020-0.030$ & 1.89 & 11.30 \\
\hline & $0.040-0.050$ & 1.97 & 10.81 & $0.040-0.050$ & 2.01 & 11.03 \\
\hline Benzene & $0.025-0.050$ & 0.77 & 10.12 & $0.020-0.050$ & 2.11 & 10.10 \\
\hline \multirow[t]{2}{*}{$298 \mathrm{~K}$} & 0.049-0.099 & 1.08 & 9.72 & $0.050-0.101$ & 2.40 & 9.42 \\
\hline & $0.250-0.298$ & 0.69 & 9.03 & $0.250-0.301$ & 2.11 & 9.20 \\
\hline Nitrogen & $0.009-0.013$ & 3.08 & 10.82 & $0.005-0.006$ & 3.85 & 11.15 \\
\hline \multirow[t]{2}{*}{$77 \mathrm{~K}$} & $0.025-0.034$ & 2.76 & 9.84 & $0.026-0.036$ & 4.75 & 10.09 \\
\hline & $0.052-0.071$ & 2.06 & 9.11 & $0.055-0.074$ & 4.51 & 9.06 \\
\hline
\end{tabular}


Table 4 Effect of carbons on cigarette smoke yields

\begin{tabular}{llll}
\hline Filter additive & \multicolumn{4}{l}{ Toxicant Yield $(\mu \mathrm{g} / \mathrm{cig})(\underline{\text { Standard Deviation }})(\boldsymbol{\%}$ Removal$)$} \\
\cline { 2 - 4 } & Acetaldehyde & Acrylonitrile & Benzene \\
\hline None & $584(\underline{40})$ & $8.7(\underline{0.2})$ & $32.0(\underline{1.7})$ \\
Nutshell Carbon & $384(\underline{20})(\mathbf{3 4})$ & $4.8(\underline{0.4})(\mathbf{4 4})$ & $18.2(\underline{2.0})(\mathbf{4 3})$ \\
Resin based Carbon & $289 \underline{(37})(\mathbf{5 0})$ & $1.4(\underline{0.1})(\mathbf{8 3})$ & $5.1(\underline{0.1})(\mathbf{8 4})$
\end{tabular}

model') and the dominance of ultramicropores as revealed by the DR method. These higher rates do of course apply to significantly higher volumes of micropore filling for the resin-based material. It is unclear why the rate constants for acrylonitrile do not follow the same trend.

Although nitrogen adsorption at $77 \mathrm{~K}$ is one of the main methods used for active carbon porosity characterisation studies, in practical terms, the temperature of adsorption is very low, especially for example, when compared to smoking temperatures. Nonetheless, the nitrogen data do show higher rate constants, and therefore faster kinetics than the other three smoke constituent vapours.

The effects of the different pore structures (and related adsorption kinetics) of the carbons on the dynamic removal of selected smoke toxicants, assessed using standard ISO smoking conditions, are shown in Table 4.

As can be seen, the resin based carbon, which displays the higher total and micropore volumes and which also yields the higher adsorption rate constants removes significantly more of the toxicants studied than the nutshell material.

\section{Conclusions}

The characteristic data, obtained using the Dubinin approach to adsorption, for nitrogen and three organic vapours present in cigarette smoke indicate a monomodal distribution of pores, mainly in the ultramicropore region, with a nominal volume of $0.4 \mathrm{~cm}^{3} \mathrm{~g}^{-1}$, for the nutshell carbon. The resin based material has a higher micropore volume, around $0.7 \mathrm{~cm}^{3} \mathrm{~g}^{-1}$, with a significant volume of wider supermicropores plus an additional volume of meso and macro pores which take the total pore volume over $1 \mathrm{~cm}^{3} \mathrm{~g}^{-1}$.

The effects of these differences on the adsorption kinetics of the test vapours (which are of diverse molecular characteristics) are observed as higher adsorption rate constants (with the exception of acrylonitrile) for the micropore filling region of resin-based material which establishes the transport properties of the wider pores in this material and their potential significance for non-equilibrium adsorption uses. The rates for the resin carbon studied also apply to significantly higher volumes of micropores than those present in the nutshell material. In dynamic smoking tests, where the contact times are very low (of the order of milliseconds), the resin based carbon performs significantly better by removing approximately $15-40 \%$ more toxicant by weight than the nutshell material.

The classical Dubinin-Radushkevich approach is shown to give a comprehensive characterisation of the two carbons; it clearly allows comparison of their structural differences and provides a basis for understanding their adsorption performance. Interestingly, the negative deviations, frequently observed in DR plots at high values of $\log ^{2}\left(p^{s} / p\right)$ i.e. at low relative pressure, and often ascribed to activated diffusion in (ultra) micropores, which results in non-equilibrium effects, are less prevalent for the resin based carbon. Hence the data presented establish a semi-quantitative relationship between pore size distribution and energy in relation to adsorption kinetics; the wider and more heterogeneous porosity resulting in higher rate constants for the resin based carbon compared to the ultramicroporous nutshell material.

Acknowledgement We gratefully acknowledge Dr. Jacek Jagiello (Micromeritics, USA) for help and advise regarding the DFT analysis of nitrogen adsorption data.

Open Access This article is distributed under the terms of the Creative Commons Attribution Noncommercial License which permits any noncommercial use, distribution, and reproduction in any medium, provided the original author(s) and source are credited.

\section{References}

Adamson, A.W.: Physical Chemistry of Surfaces, p. 609, 5th edn. Wiley, New York (1990)

Bansal, R.C., Goyal, M.: Activated Carbon Adsorption. CRC Press, Boca Raton (2005)

Bradley, R.H.: The adsorption of vapours by activated and heat-treated microporous carbons, part 1: characterisation of pore structure using the Dubinin-Polanyi approach. Carbon 29, 893-897 (1991)

Branton, P.J., et al.: The effect of carbon pore structure on the adsorption of cigarette smoke vapour phase compounds. Carbon 47, 1005-1011 (2009)

Brunauer, S., et al.: Adsorption of gases in multimolecular layers. J. Am. Chem. Soc. 60, 309-319 (1938)

Dubinin, M.M.: Fundamentals of the theory of adsorption in micropores of carbon adsorbents: characteristics of their adsorption properties and microporous structures. Carbon 27, 457-467 (1989)

Dubinin, M., Astakhov, V.A.: Development of the concepts of volume filling of micropores in the adsorption of gases and vapours by microporous adsorbents. Adv. Chem. Ser. 102, 69 (1971) 
Dubinin, M.M., Radushkevich, L.V.: Equation of the characteristic curve of activated charcoal. Proc. Acad. Sci. USSR 55, 331 (1947)

Dubinin, M.M., Timofeyev, P.: Adsorption of vapours on active carbons in relation to the properties of the adsorbate. Dokl. Akad. Nauk SSSR 54, 701-704 (1946)

Dubinin, M.M., et al.: Integrated study of the porous structure of active carbons from carbonized sucrose. Carbon 2, 261 (1964)

Fletcher, A.J., et al.: Role of surface functional groups in the adsorption kinetics of water vapour on microporous carbons. J. Phys. Chem. C 111, 8349-8359 (2007)

Gregg, S.J., Sing, K.S.W.: Adsorption, Surface Area and Porosity, 2nd edn., p. 41. Academic Press, London (1982)

Jagiello, J., et al.: Using DFT analysis of adsorption data of multiple gases including $\mathrm{H}_{2}$ for the comprehensive characterisation of microporous carbons. Carbon 45, 1066-1071 (2007)

Marsh, H., Rand, B.: In: Proc. 3rd Conf. on Carbon and Graphite, p. 172. SCI, London (1970)

Mola, M., et al.: The characterisation and evaluation of activated carbon in a cigarette filter. Adsorption 14, 335-341 (2008)

Rao, M.B., et al.: Mathematical modeling of diffusive potentials within carbon molecular sieves. In: Amer. Carbon Soc., Ext Abs. 17th Biennial Carbon Conf., Lexington, Kentucky, p. 114 (1985)
Reid, C.R., Thomas, K.M.: Adsorption kinetics and size exclusion properties of probe molecules for the selective porosity in a carbon molecular sieve used for air separation. J. Phys. Chem. B 105, 10619-10629 (2001)

Rutherford, S.W., Coons, J.E.: Equilibrium and kinetics of water adsorption in active carbon molecular sieve: theory and experiment. Langmuir 20, 8681-8687 (2004)

Stoecki, F.: Recent developments in Dubinin's theory. Carbon 36, 363 (1997)

Stoeckli, F.: Dubinins theory and its contribution to adsorption science. Russ. Chem. Bull. 12, 2265-2272 (2001)

Stoeckli, F., et al.: The comparison of experimental and calculated pore size distributions of activated carbons. Carbon 40, 383-388 (2002)

Sugden, S.J.: The determination of surface tension from the maximum pressure in bubbles, part II. J. Chem. Soc., Trans. 125, 27 (1924)

Thomsen, H.V.: International reference method for the smoking of cigarettes. Recent Adv. Tob. Sci. 18, 69-94 (1992)

Toda, Y., et al.: Fine structure of carbonized coals. Carbon 8, 565 (1970) 